\title{
Motivation and Physical Activity: Differences Between High School and University Students in Spain
}

Perceptual and Motor Skills $0(0) \mathrm{I}-14$

(C) The Author(s) 2018

Reprints and permissions: sagepub.com/journalsPermissions.nav DOI: $10.1|77 / 003| 5|25| 8788743$ journals.sagepub.com/home/pms

@SAGE

\section{Javier Sevil}

\author{
Javier S. Serrano' $\left(\mathbb{D}\right.$, Pedro A. Sánchez-Miguel $^{2}(\mathbb{D}$, \\ Juan J. Pulido-González ${ }^{3}$, Alba Práxedes ${ }^{3}$, and \\ David Sánchez-Oliva ${ }^{3}$
}

\begin{abstract}
Grounded in self-determination theory, this study aimed first to examine differences in motivation for physical activity (PA) and habitual PA levels between adolescents and university students in Spain. The second aim was to examine differences in the degree of association between their intrinsic motivation and amotivation for PA and habitual PA levels in both samples. We studied 2,699 students (I,833 high school and 866 university; mean age $=18.83$, standard deviation $=4.12$ years) who completed the International Physical Activity Questionnaire-Short Form and two dimensions of the Behavioral Regulation in Exercise Questionnaire. High school students, relative to university students, self-reported significantly higher intrinsic motivation and higher PA levels for each type of PA intensity (i.e., walk, moderate, and vigorous); high school students also self-reported significantly lower amotivation than university students. The degree of association between the total metabolic equivalents of task
\end{abstract}

\footnotetext{
'Faculty of Health and Sport Sciences, Department of Didactics of the Musical, Plastic and Body Expression, University of Zaragoza, Huesca, Spain

${ }^{2}$ Faculty of Teaching Training, Department of Didactics of Music, Plastic and Body Expression, University of Extremadura, Cáceres, Spain

${ }^{3}$ Faculty of Sport Sciences, Department of Didactics of Music, Plastic and Body Expression, University of Extremadura, Cáceres, Spain
}

Corresponding Author:

Javier S. Serrano, Faculty of Health and Sport Sciences, University of Zaragoza, Plaza Universidad, 3, Javier Sevil Pl, Spain. 
and intrinsic motivation was higher among high school (versus) university students. This study shows the need to design intervention strategies to enhance PA levels and intrinsic motivation in university students.

\section{Keywords}

health promotion, physical activity, motivation, transitioning, young people

\section{Introduction}

A substantial body of research has shown that regular participation in moderate to vigorous physical activity (MVPA) provides health benefits in every age range (Reiner, Niermann, Jekauc, \& Woll, 2013). Despite these acknowledged benefits, a high percentage of high school (Cooper et al., 2015) and university students (Pengpid et al., 2015) do not meet well accepted physical activity (PA) guidelines. The World Health Organization (2010) has recommanded that childran and ado lescents aged 5 to 17 years should have at le Engberg, E., Alen, M., Kukkonenadults, the recommendation is for at least 1 Harjula, K., Peltonen, J. E., intensity activity, 75 minutes of vigorous a Tikkanen, H. O., \& Pekkarinen, H. A systematic review of PA changes during(2012). Life events and change in levels start to slightly decrease from midDumith, Gigante, \& Domingues, 2011). O decrease into adulthood, particularly with leisure time physical activity. Sports Medicine, 42(5), 433-447. university (Ullrich-French, Cox, \& Bumpus, 2013), possibly because of physical, social, and psychological changes (Engberg et al., 2012). [AQ1] Therefore, promoting PA among young adults has become a major public health priority.

In considerations of potential antecedents of increased PA (e.g., social/ cultural influences, psychological/cognitive, demographic/biological, and environmental), the last few decades have seen increased interest in motivation studies to better understand PA participation (Duncan, Hall, Wilson, \& Jenny, 2010). Motivation has been highlighted as one of the most important factors for improving PA levels (Bauman et al., 2012; Rhodes, Janssen, Bredin, Warburton, \& Bauman, 2017). However, in line with the decrease in PA with increasing age, a 1-year prospective study showed a significant decline in motivation for PA as students transition from high school to university (Ullrich-French et al., 2013). Self-determination theory (Deci \& Ryan, 1985) has been the most widely applied theoretical framework for studying students' motivations and their association with PA levels (Owen, Smith, Lubans, Ng, \& Lonsdale, 2014; Teixeira, Carraça, Markland, Silva, \& Ryan, 2012). Following a motivational continuum suggested by self-determination theory (Deci \& Ryan, 1985), different types of motivation with varying degrees of self-determination have been identified: intrinsic motivation, extrinsic motivation, and amotivation. A person is said to be intrinsically motivated when he or she engages in an 
activity for feelings of enjoyment, pleasure, interest, and satisfaction that are inherent to the participation itself. From the highest to the lowest level of self-determination, extrinsic motivation is divided into four regulation types: integrated, identified, introjected, and external regulation. A person is said to be extrinsically motivated when the activity is controlled by contingencies external to the individual, such as obtaining rewards, avoiding punishments, or meeting external expectations. Finally, the lowest level of self-determination is amotivation, represented by an absence of motivation, either intrinsic or extrinsic (Deci \& Ryan, 1985).

Past studies have shown that intrinsic motivation is positively related to higher levels of PA among children and adolescents (Owen et al., 2014) and among university students (Quartiroli \& Maeda, 2014). Furthermore, Owen et al. (2014) found that amotivation had a weak negative association with PA in children and adolescents $(\rho=-.11$ to -.21$)$. In contrast, a systematic review conducted by Teixeira et al. (2012) in an adult sample, found no relationship between amotivation and PA behavior. Despite a vast number of studies on adolescents and university students examining the relationship between motivation for leisure-time PA and PA levels, to our knowledge, no studies have examined whether the relationship between intrinsic motivation and amotivation and PA levels differ among high school and university students. A greater understanding of these associations would better inform and help to design intervention strategies focused on enhancing intrinsic motivation as a path toward enhanced PA. In Spain, we are aware of only one cross-sectional study that has assessed PA levels in high school and university students (Cocca, Liukkonen, Mayorga-Vega, \& Viciana-Ramírez, 2014); this study showed low compliance with PA guidelines among university students and psychological motivation was not measured. These mixed and sometimes sparse research findings justify more research to deepen knowledge of the relationship between both variables.

The first aim of this study was to determine whether there were differences in PA levels and motivation for PA between high school and university students in Spain. A second objective was to examine any differences in the degree of association between intrinsic motivation or amotivation for PA and PA levels in both samples. We hypothesized that university students would show lower intrinsic motivation values and lower PA levels and that they would also show higher amotivation values than high school adolescents. We also hypothesized that the relationship between both motivational regulations and PA levels would be stronger among high school than among university students.

\section{Method}

\section{Participants and Procedure}

We selected student participants by simple random sampling, taking into account the population from schools and faculties situated in Cáceres, Spain. 
Schools and faculties were chosen according to their geographical location in the region (north-south gradient to be representative). Our final sample comprised 2,699 students $(1,441$ males, 873 females; mean age $=18.83$, standard deviation $[S D]=4.12$ years). Their ages ranged from 14 to 49 years. Of our total sample, 1,833 participants were high school students (960 males, 873 females; mean age $=15.33, S D=3.32$ years) from 22 different high schools, and 866 were university students (481 males, 385 females; mean age $=21.34, S D=4.51$ years) from 12 different disciplines. We eliminated 70 participants $(66$ high school students) because of incorrect completion of the different instruments, leaving a completed response rate of $97.47 \%$. In the case of the high school students (who were under age), we obtained informed consent from their parents prior to the students' participation in the study. Both high school and university students also gave their written consent to voluntarily participate in the research.

The study was approved by the Ethics Committee of the University of Cáceres, Spain. First, permission was obtained from the 22 schools and 12 university disciplines, specifying a date to collect the questionnaires. Prior to giving the instruments to students, we explained to all participants the general purpose of the study and gave a deeper explanation of the concepts "moderate" and "vigorous" PA, with several examples of different physical activities and sports. Participants then completed the questionnaires in this study (see subsequent text) within their classroom; the time required was approximately 15 to 20 minutes.

\section{Measures}

Motivation for physical activity. We measured intrinsic motivation and amotivation for PA with the Spanish adaptation (González-Cutre, Sicilia, \& Fernández, 2010) of the Behavioral Regulation in Exercise Questionnaire (BREQ-3; Wilson, Rodgers, Loitz, \& Scime, 2006). Each factor contained four items: intrinsic motivation (e.g., "Because I feel pleasure and satisfaction when I do exercise"), and amotivation (e.g., "I think I am wasting my time with exercise") that followed the statement "I practise physical activity because ..." Items were rated on a 5-point Likert scale $(1=$ strongly disagree, $5=$ strongly agree $)$. Cronbach's alpha values reflecting item reliability among participants in this study were .87 for intrinsic motivation and .77 for amotivation.

Physical activity levels. To measure habitual PA levels, participants completed the International Physical Activity Questionnaire-Short Form (IPAQ-SF; Booth, 2000). This questionnaire has been validated in 12 countries (Craig et al., 2003); it has shown acceptable psychometric properties to assess PA levels with good test-retest reliability after 1 week (Spearman correlation coefficient values were around 0.8). Several different studies have shown the Spanish validity of IPAQ-SF for measuring PA levels through the correlations obtained in 
the registered values with accelerometers in adolescents $(r=.31, p<.001$; Aibar, García-González, Abarca-Sos, Murillo, \& Zaragoza, 2016) and university students $(r=.49, p<.001$; Rodríguez-Muñoz, Corella, Abarca-Sos, \& Zaragoza, 2017). According to the official IPAQ scoring protocol, we calculated total daily PA by summing the product of reported time in PA within each intensity in terms of metabolic equivalents of task (METs) per week. We used the following standard values in METs, according to the intensity of the activity: walking (3.3 METs), moderate PA (4 METs), and vigorous PA (8 METs; IPAQ Research Committee, 2005).

\section{Statistical Analysis}

Data were analyzed using the SPSS 21.0 statistical package. We conducted the Kolmogorov-Smirnov test to examine the normality of data distribution. As a result, we then used parametric statistics ( $p>.05$ in all cases). We calculated descriptive statistics for all variables (means and $S D$ s), and we examined the internal consistency of each factor with Cronbach's alpha. We conducted Pearson correlation analysis among the different variables of the study, and we calculated a one-way analysis of covariance with gender as a covariate to assess possible differences between high school and university students on PA levels, intrinsic motivation, and amotivation. Finally, we performed a series of multiple regression analyses using Restricted Maximum Likelihood as method of estimation, with total METs per week as the dependent variable in order to ascertain whether the relationship with both motivational regulations varied between high school and university students. In line with Field's (2009) recommendations, we initially tested an empty model without any predictors (Model 0 ). In Model 1, we included the students' educational level as a between-participants factor, and we introduced gender as a covariate. In Model 2, we added intrinsic motivation and amotivation as predictors (standardized scores). Last, in Model 3, we included interaction effects between educational level and types of motivation. The significance level for all statistical tests was set as $p<.001$.

\section{Results}

Descriptive statistics and correlational analysis are shown in Table 1. Bivariate correlation analysis revealed that intrinsic motivation was positively related to moderate and vigorous PA (with a greater correlation coefficient for vigorous PA) and to total METs, whereas amotivation was negatively associated with moderate and vigorous PA (the greatest correlation coefficient was again found in vigorous PA) and in total METs.

As illustrated in Table 2, high school students showed significantly higher PA (i.e., walking, moderate and vigorous PA, and total METs) than university students $(p<.001)$. With respect to type of motivation, high school students 
Table I. Descriptive and Correlational Analysis.

\begin{tabular}{lrrrrrrr}
\hline & \multicolumn{1}{c}{ Mean } & \multicolumn{1}{c}{ SD } & \multicolumn{1}{c}{ I } & \multicolumn{1}{c}{2} & 3 & 4 & 5 \\
\hline I. METs walking & $1,157.82$ & $1,382.96$ & - & & & & \\
2. METs moderate & 874.99 & $1,058.28$ & $.22^{*}$ & - & & & \\
$\quad$ activities & & & & & & & \\
3. METs vigorous & $2,231.01$ & $2,509.53$ & $.12^{*}$ & $.45^{*}$ & - & & \\
$\quad$ activities & & & & & & & \\
4. Total METs & $3,489.38$ & $3,354.48$ & $.5 I^{*}$ & $.65^{*}$ & $.86^{*}$ & - & \\
5. Intrinsic motivation & 3.91 & 1.08 & .04 & $.20^{*}$ & $.22^{*}$ & $.22^{*}$ & - \\
6. Amotivation & 1.59 & .96 & -.04 & $-.10^{*}$ & $-.11^{*}$ & $-.13^{*}$ & $-.69 *$ \\
\hline
\end{tabular}

METs = metabolic equivalents of task; $S D=$ standard deviation. $* p<.001$.

Table 2. Differences Between High School Scholars and University Students in PA Levels and the Type of Motivation.

\begin{tabular}{|c|c|c|c|c|c|c|}
\hline & \multicolumn{2}{|c|}{ High school scholars } & \multicolumn{2}{|c|}{ Universities } & \multirow[b]{2}{*}{$F$} & \multirow[b]{2}{*}{$p$} \\
\hline & Mean & $S D$ & Mean & $S D$ & & \\
\hline METs walking & I,338.58 & I,567.92 & 852.88 & 919.40 & 69.025 & $<.001$ \\
\hline $\begin{array}{l}\text { METs moderate } \\
\text { activities }\end{array}$ & $1,186.98$ & $\mathrm{I}, 175.30$ & 415.66 & 617.73 & 314.03 & $<.001$ \\
\hline $\begin{array}{l}\text { METs vigorous } \\
\text { activities }\end{array}$ & $2,830.31$ & $2,747.09$ & $\mathrm{I}, 325.84$ & $\mathrm{I}, 747.8 \mathrm{I}$ & 204.825 & $<.001$ \\
\hline Total METs & $3,9 \mid 2.22$ & $3,697.81$ & $2,594.38$ & $2,226.37$ & 93.899 & $<.001$ \\
\hline Intrinsic motivation & 4.05 & .96 & 3.61 & 1.25 & 100.37 & $<.001$ \\
\hline Amotivation & 1.52 & .83 & 1.72 & 1.19 & 24.048 & $<.001$ \\
\hline
\end{tabular}

METs = metabolic equivalents of task; SD = standard deviation.

also showed significantly higher intrinsic motivation $(p<.001)$ and significantly lower amotivation than university students $(p<.001)$.

Table 3 shows a summary of model estimates obtained in the different regression analyses of total METs. Initially, the null model (Model 0) was tested, including only the intercept. The estimation of the model was 3,489.38, which made reference to the average level of total METs in the total sample. This model allowed assessment of the improvement of the total adjustment with respect to the following models tested, in terms of global fit (deviance). The current work indicates how, in every case, each model demonstrated a fit that was better than the former model, which explains the logic used to include the predictive variables. Second, Model 1 included the groups (high school or 


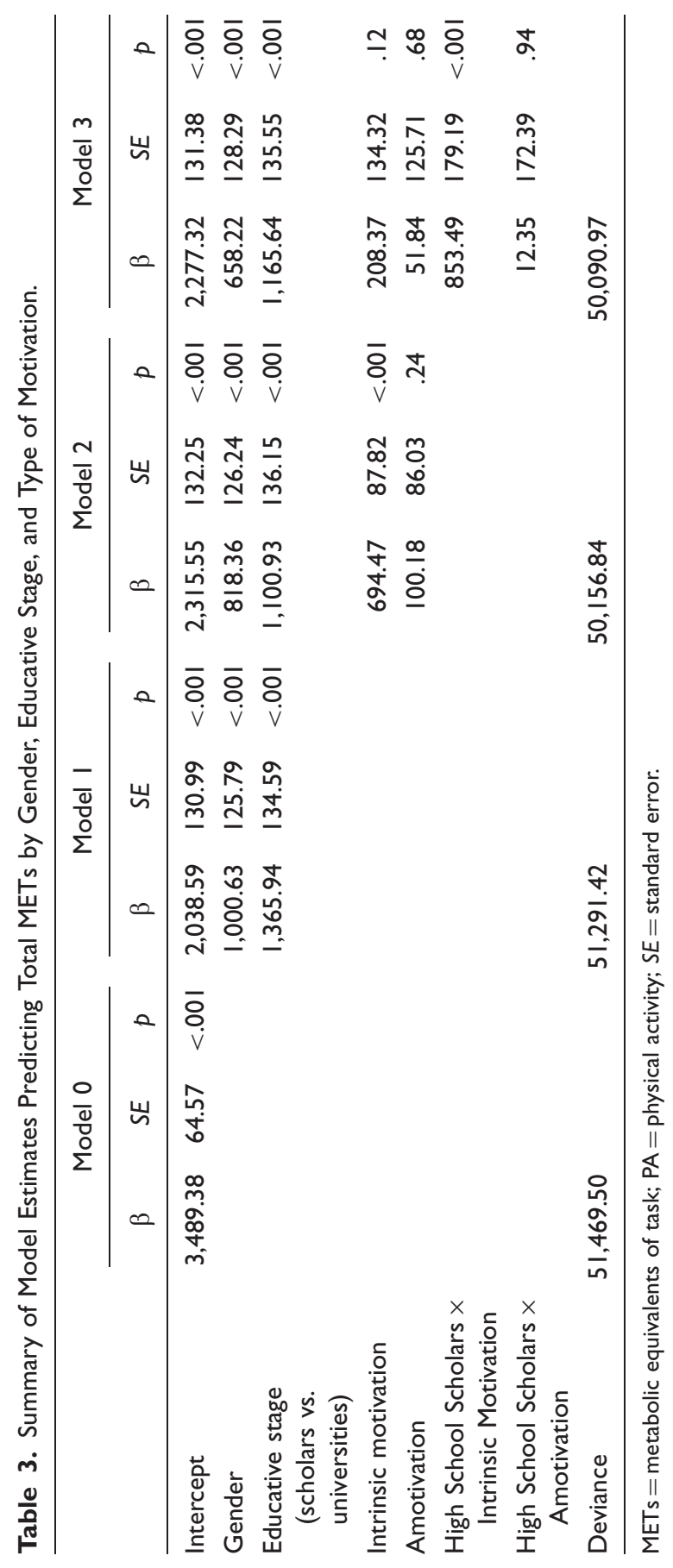


university students) as between-persons factor. In this model, the intercept is the estimate of total METs in the university students group, whereas the group effect is the mean difference with respect to the high school students group. These outcomes were consistent with those found in the one-way analysis of variance, demonstrating that after controlling for gender, the university students $(\beta=2,038.59)$ had a significantly lower METs score than high school students $(\beta=2,038.59+1,365.94=3,404.53)$.

Later, Model 2 added intrinsic motivation and amotivation as covariates. First, after controlling for gender, intrinsic motivation and amotivation differences in various PA levels were shown in both high school and university students. Further, intrinsic motivation positively predicted PA levels $(p<.001)$. Specifically, the estimation indicated that as intrinsic motivation increased by one unit, the level of PA was raised by 694.47 METs. No significant results were found in the relationship between amotivation and PA levels. Nevertheless, as we entered the educational level as a factor, this finding only refers to the university students (reference group).

Last, Model 3 added the interaction between the group and each behavioral regulation, which yielded information about the association between the type of motivation and total METs in both high school and university students. Specifically, the main effect of this model (intrinsic motivation) is the regression estimate of this variable in the reference group (university students), whereas the interactions effects refer to the differences in the regression coefficients between high school and university students. Results showed that, after controlling for gender, the relationship between intrinsic motivation and total METs was significantly stronger in high school $(\beta=208.37+853.49=1,061.86)$ than in university students $(\beta=208.37)$. This finding suggests that in the high school students, when the intrinsic motivation increased by one unit, the model estimated that the PA level was raised by 1,061.86 METs. Regarding the amotivation, in both groups (i.e., high school and university students), the association between amotivation and total METs was not significant $(p>.05)$.

\section{Discussion}

The first aim of this study was to examine possible differences in intrinsic motivation for PA and amotivation as well as PA levels between high school and university students of Spain. Results showed that high school students reported significantly higher values than university students in PA levels (i.e., walking, moderate, and vigorous) and total METs. These findings are consistent with past studies that suggested, by contrast, that the university population is particularly vulnerable to reduced PA levels, showing that between $40 \%$ and $50 \%$ of university students are inactive (Haase, Steptoe, Sallis, \& Wardle, 2004). Similarly, Cocca et al. (2014) showed that university students were less active than secondary school students. Accordingly, public health 
strategies should focus their attention on promoting initiatives to increase PA levels among university students.

A possible explanation for lower PA levels among university students may be that the transition from high school to working life is associated with lifestyle changes that can reduce PA levels (Molina-García, Queralt, Castillo, \& Sallis, 2015). Further, other authors have emphasized that the lifestyle change from high school to university is most often caused by the change of regular residence that creates a wide variety of leisure-time activities (Moreno-Gómez et al., 2012). Romaguera et al. (2011) suggested that there are changes in personal (i.e., lack of time), social (i.e., habits of PA practice), and lifestyle habits (e.g., screen time, diet, tobacco, and alcohol consumption) that may influence university students' PA levels. The disappearance of physical education (PE) as a compulsory subject in the university setting may be a further reason for the decline in PA levels, because of PE's direct and indirect contributions in secondary school toward increasing MVPA levels (Hollis et al., 2017; Slingerland \& Borghouts, 2011).

Our study's findings also gave evidence that high school students showed significantly higher values for intrinsic motivation for PA than university students as well as relatively lower scores in amotivation. The present findings are consistent with the longitudinal study carried out by Ullrich-French et al. (2013) showing that amotivation increased across the transition to the university. However, Ullrich-French et al.'s results differed from ours in that they found no significant differences in intrinsic motivation between these populations. Our findings are in line with another study conducted with university students suggesting that one of the main barriers to their practice of PA was lack of motivation (Biddle, Atkin, Cavill, \& Foster, 2011).

This study also sought to examine differences in the degree of association between intrinsic motivation and amotivation for PA and PA levels in both samples. First, these results highlighted the importance of intrinsic motivation for students' PA levels (i.e., moderate and vigorous PA) and total METs, as our data showed a positive relationship between both variables. These findings are consistent with those found in other studies with adolescents (Sebire, Jago, Fox, Edwards, \& Thompson, 2013) and university students (Ingledew, Markland, \& Ferguson, 2009; Ullrich-French et al., 2013). Hence, according to the relationship between intrinsic motivation and total METs in these two student populations, our results further revealed that the relationship between these two variables was statistically higher among high school students, relative to university students. In the high school students group, the intrinsic motives of PA practice itself (i.e., enjoyment, satisfaction, pleasure) played a crucial role in predicting students' PA levels. A possible explanation for these findings is that university students engage in PA for health or social reasons (Roberts, Reeves, \& Ryrie, 2015). Indeed, González-Cutre et al. (2010) showed, in university populations, integrated regulation could be more important toward becoming more physically active than intrinsic motivation. Thus, intrinsic motives appear to be 
less important for PA activity in university than in high school students. To illustrate, those university students who have a higher intrinsic motivation for PA could perceive frequent barriers to PA at this educational level that affect their leisure-time PA habits while those university students who have integrated PA into their lifestyle might organize their free time to maintain higher levels of PA behavior (Pelletier \& Sarrazin, 2008). To maintain or increase PA levels through the university transition, it seems necessary to develop intervention programs that improve not only the PA levels, but also intrinsic motivation for them. Recent studies suggest that PE lessons could play a key role in this effort (Sun, Li, \& Shen, 2017).

From our regression analysis, amotivation did not emerge as a negative predictor of PA practice among the combined populations of high school and university students. Nevertheless, the correlation analysis found a negative and weak relationship between amotivation and moderate and vigorous PA and total METs, with the exception of walking. Some prior studies with adolescents (Owen, Astell-Burt, \& Lonsdale, 2013) have also shown a negative and weak association among these variables. However, the systematic review by Teixeira et al. (2012) showed that there was no relationship between amotivation and PA practice among adults. A possible justification for the low association between these two variables might be that there are individuals who, despite evidence they are not motivated for PA practice, are aware of its benefits and therefore decide to include PA in their lifestyle even while they do not find it an attractive activity (Haerens, Kirk, Cardon, De Bourdeaudhuij, \& Vansteenkiste, 2010). Thus, our results only partially confirmed our hypothesis, making it necessary to consider a person-centered approach of identifying motivational profiles for PA and evaluating their differences on PA levels.

Regarding our study's limitations, we only assessed PA levels with a selfreport instrument (IPAQ-SF). Nevertheless, several studies supporting the validity of the IPAQ-SF in adolescents and university students and our large sample of student research participants help to justify the failure to utilize an objective measure of PA (e.g., accelerometers). In addition, our reliance on a cross-sectional research design did not permit causal conclusions with regard to these variables. A further limitation was that our study did not include the different types of extrinsic motivation proposed by self-determination theory. A future study might utilize a longitudinal design and assess PA levels objectively along with different types of motivation, with the aim of examining those variables as high school students transition to university. Further experimental studies are also required to study effective means of increasing PA levels and motivation, particularly in university students.

In sum, our results found the transition from high school to university a critical period to focus on maintaining PA levels that generally decline. This study emphasized the importance of intrinsic motivation in efforts to increase PA levels as high school students transition to university students. 
PA intervention programs for university students must be addressed to their interests and preferences, and both PE curricular and extracurricular activities will likely be needed to enhance students' intrinsic motivation.

\section{Declaration of Conflicting Interests}

The author(s) declared no potential conflicts of interest with respect to the research, authorship, and/or publication of this article.

\section{Funding}

The author(s) received no financial support for the research, authorship, and/or publication of this article.

\section{Javier Sevil}

Javier S. Serrano (D) http://orcid.org/0000-0002-2077-1983

Pedro A. Sánchez-Miguel (D) http://orcid.org/0000-0002-1660-535X

\section{References}

Aibar, A., García-González, L., Abarca-Sos, A., Murillo, B., \& Zaragoza, J. (2016). Analizando la validación del International Physical Activity Questionnaire en jóvenes adolescentes: Un protocolo modificado para la recogida de los datos. [Testing the validity of the International Physical Activity Questionnaire in early Spanish adolescents: A modified protocol for data collection]. SPORT TK-Revista EuroAmericana de Ciencias del Deporte, 5(2), 123-132.

Bauman, A. E., Reis, R. S., Sallis, J. F., Wells, J. C., Loos, R. J., Martin, B. W., \& Lancet Physical Activity Series Working Group. (2012). Correlates of physical activity: Why are some people physically active and others not? The Lancet, 380(9838), 258-271.

Biddle, S. J. H., Atkin, A. J., Cavill, N., \& Foster, C. (2011). Correlates of physical activity in youth: A review of quantitative systematic reviews. International Review of Sport and Exercise Psychology, 4(1), 25-49.

Booth, M. L. (2000). Assessment of physical activity: An international perspective. Research Quarterly for Exercise and Sport, 71(2), 114-120.

Cocca, A., Liukkonen, J., Mayorga-Vega, D., \& Viciana-Ramírez, J. (2014). Healthrelated physical activity levels in Spanish youth and young adults. Perceptual and Motor Skills, 118(1), 247-260.

Cooper, A. R., Goodman, A., Page, A. S., Sherar, L. B., Esliger, D. W., van Sluijs, E. M., ... Froberg, K. (2015). Objectively measured physical activity and sedentary time in youth: The International children's accelerometry database (ICAD). International Journal of Behavioral Nutrition and Physical Activity, 12(1), 113.

Craig, C. L., Marshall, A. L., Sjostrom, M., Bauman, A. E., Booth, M. L., Ainsworth, B. E.,... Oja, P. (2003). International physical activity questionnaire: 12-Country reliability and validity. Medicine and Science in Sports and Exercise, 35(8), 1381-1395.

Deci, E. L., \& Ryan, R. M. (1985). Intrinsic motivation and self-determination in human behavior. New York, NY: Plenum Press. 
Dumith, S. C., Gigante, D. P., \& Domingues, M. R. (2011). Physical activity change during adolescence: A systematic review and a pooled analysis. International Journal of Epidemiology, 40(3), 685-698.

Duncan, L. R., Hall, C. R., Wilson, P. M., \& Jenny, O. (2010). Exercise motivation: a cross-sectional analysis examining its relationships with frequency, intensity, and duration of exercise. International Journal of Behavioral Nutrition and Physical Activity, 7 , $1-9$.

Field, A. (2009). Discovering statistics using SPSS. Berlin, Germany: Sage.

González-Cutre, D., Sicilia, A., \& Fernández, A. (2010). Hacia una mayor comprensión de la motivación en el ejercicio físico: Medición de la regulación integrada en el contexto español [Towards a better understanding of motivation for physical exercise: A measure of integrated regulation in the Spanish context]. Psicothema, 22(4), 841-847.

Haase, A., Steptoe, A., Sallis, J. F., \& Wardle, J. (2004). Leisure-time physical activity in university students from 23 countries: Associations with health beliefs, risk awareness, and national economic development. Preventive Medicine, 39(1), 182-190.

Haerens, L., Kirk, D., Cardon, G., De Bourdeaudhuij, I., \& Vansteenkiste, M. (2010). Motivational profiles for secondary school physical education and its relationship to the adoption of a physically active lifestyle among university students. European Physical Education Review, 16(2), 117-139.

Hollis, J. L., Sutherland, R., Williams, A. J., Campbell, E., Nathan, N., Wolfenden, L., ... Wiggers, J. (2017). A systematic review and meta-analysis of moderate-to-vigorous physical activity levels in secondary school physical education lessons. International Journal of Behavioral Nutrition and Physical Activity, 14(1), 52.

Ingledew, D. K., Markland, D., \& Ferguson, E. (2009). Three levels of exercise motivation. Applied Psychology: Health and Well-being, 1(3), 336-355.

IPAQ Research Committee (2005). Guidelines for the data processing and analysis of the International Physical Activity Questionnaire [AQ2].

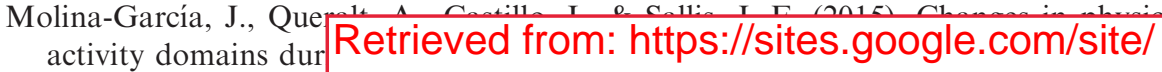
mental correlates. $J o$ theipaq/scoring-protocol

Moreno-Gómez, C., Romaguera-Bosch, D., Tauler-Riera, P., Bennasar-Veny, M., Pericas-Beltran, J., Martinez-Andreu, S., \& Aguilo-Pons, A. (2012). Clustering of lifestyle factors in Spanish university students: The relationship between smoking, alcohol consumption, physical activity and diet quality. Public Health Nutrition, 15(11), 2131-2139.

Owen, K. B., Astell-Burt, T., \& Lonsdale, C. (2013). The relationship between selfdetermined motivation and physical activity in adolescent boys. Journal of Adolescent Health, 53, 420-422.

Owen, K. B., Smith, J., Lubans, D. R., Ng, J. Y. Y., \& Lonsdale, C. (2014). Self-determined motivation and physical activity in children and adolescents: A systematic review and meta-analysis. Preventive Medicine, 67, 270-279.

Pelletier, L. G., \& Sarrazin, P. (2008). Measurement issues in self-determination theory and sport. In M. S. Hagger \& N. L. D. Chatzisarantis (Eds.), Intrinsic motivation and 
self-determination in exercise and sport [AQ3](pp. M-D). Champaign, IL: Human Kinetics.

Pengpid, S., Peltzer, K., Kassean, H. K., Tsala, J. P. T., Sychareun, V., \& MüllerRiemenschneider, F. (2015). Physical inactivity and associated factors among university students in 23 low-, middle-and high-income countries. International Journal of Public Health, 60(5), 539-549.

Quartiroli, A., \& Maeda, H. (2014). Self-determined engagement in physical activity and sedentary behaviors of US college students. International Journal of Exercise Science, 7(1), 87-97.

Reiner, M., Niermann, C., Jekauc, D., \& Woll, A. (2013). Long-term health benefits of physical activity-A systematic review of longitudinal studies. BMC Public Health, 13, 813.

Rhodes, R. E., Janssen, I., Bredin, S. S., Warburton, D. E., \& Bauman, A. (2017). Physical activity: Health impact, prevalence, correlates and interventions. Psychology \& Health, 32(8), 942-975.

Roberts, S., Reeves, M., \& Ryrie, A. (2015). The influence of physical activity, sport and exercise motives among UK-based university students. Journal of Further and Higher Education, 39(4), 598.

Rodríguez-Muñoz, S., Corella, C., Abarca-Sos, A., \& Zaragoza, J. (2017). Validation of three short physical activity questionnaires with accelerometers among university students in Spain. The Journal of Sports Medicine and Physical Fitness, 57(12), $1660-1668$.

Romaguera, D., Tauler, P., Bennasar, M., Pericas, J., Moreno, C., Martinez, S., \& Aguilo, A. (2011). Determinants and patterns of physical activity practice among Spanish university students. Journal of Sports Sciences, 29(9), 989-997.

Sebire, S. J., Jago, R., Fox, K. R., Edwards, M. J., \& Thompson, J. L. (2013). Testing a self-determination theory model of children's physical activity motivation: A cross-sectional study. International Journal of Behavioral Nutrition and Physical Activity, 10, 111.

Slingerland, M., \& Borghouts, L. (2011). Direct and indirect influence of physical education-based interventions on physical activity: A review. Journal of Physical Activity and Health, 8(6), 866-878.

Sun, H., Li, W., \& Shen, B. (2017). Learning in physical education: A selfdetermination theory perspective. Journal of Teaching in Physical Education, 36(3), 277-291.

Teixeira, P. J., Carraça, E. V., Markland, D., Silva, M. N., \& Ryan, R. M. (2012). Exercise, physical activity, and self-determination theory: A systematic review. International Journal of Behavioral Nutrition and Physical Activity, 9, 78-108.

Ullrich-French, S., Cox, A. E., \& Bumpus, M. F. (2013). Physical activity motivation and behavior across the transition to university. Sport, Exercise, and Performance Psychology, 2(2), 90-101.

Wilson, P. M., Rodgers, W. M., Loitz, C. C., \& Scime, G. (2006). "It's who I am... really!'. The importance of integrated regulation in exercise contexts. Journal of Applied Biobehavioral Research, 11(2), 79-104.

World Health Organization. (2010). Global recommendations on physical activity for health. Geneva, Switzerland: Author. 
Author Biographies

Javier S. Serrano: II [AQ4] Javier Sevil

Pedro A. Sánchez-Miguel:

Juan J. Pulido-González:

Alba Práxedes:
Javier Sevil - PhD student in Education in the University of Zaragoza, Spain. Professor at the Faculty of Health and Sport Sciences in the University of Zaragoza. Member of the Research Group: Physical Education and Promotion of Physical Activity. Research interests: motivation in Physical Education and leisure-time Physical Activity, school-based interventions on multiple health behaviors, and teacher motivational strategies in Physical Education.

David Sánchez-Oliva: 